\title{
Normative study of the implicit causality of 100 interpersonal verbs in Spanish
}

\author{
Edurne Goikoetxea, Gema Pascual, and Joana Acha \\ Universidad de Deusto, Bilbao, Spain
}

\begin{abstract}
This study provides normative data on the implicit causality of interpersonal verbs in Spanish. Two experiments were carried out. In Experiment 1, ratings of the implicit causality of 100 verbs classified into four types (agent-patient, agent-evocator, stimulus-experiencer, and experiencer-stimulus) were examined. An offline task was used in which 105 adults and 163 children had to complete sentences containing one verb. Both age and gender effects in the causal biases were examined. In Experiment 2, reading times for sentences containing 60 verbs were analyzed. An online reading task was used in which 34 adults had to read sentences that were both congruent and incongruent with the implicit causality of the verb. The results support the effect of implicit causality in both adults and children, and they support the taxonomy used.
\end{abstract}

Basic cognitive categories, such as causality, are encoded by language, even in the meanings of isolated words. This is the case of the so-called interpersonal verbs (e.g., criticize, help), which describe interchanges between people. In addition to their explicit meanings, these verbs enclose a semantic content that helps to make the causal attribution. Some interpersonal verbs give rise to inferences that assign the cause to the grammatical subject, whereas others assign it to the grammatical object. Thus, in the case of Sentence 1 below, it is more likely to be inferred that David, and not Sara, was the cause of the action of asking for forgiveness. However, in Sentence 2, the majority would agree that it was Sara, rather than David, who induced the congratulations:

\section{David asked Sara for forgiveness.}

2. David congratulated Sara.

When the interpersonal verbs give rise to inferences that would assign the cause to the subject, they are usually called verbs with biasing toward the first name in the sentence or Noun Phrase 1 (NP1, from this point on). However, if the cause is assigned to the object, the verbs are referred to as verbs with biasing toward Noun Phrase 2 (NP2, from this point on). This causal directionality contained in the meanings of the verbs has been called implicit causality, and the present study deals with this phenomenon. Since the first empirical research by Garvey and Caramazza (1974; for the first discussion see Heider, 1958), implicit causality has been widely researched within diverse areas of psychology, such as language processing and comprehension, motivation, emotion, and social behavior, among others (for an overview, see Rudolph \& Försterling, 1997a). In psycholinguistics, for example, implicit causality is known to play a role in the comprehension of discourse, since the causal inferences are part of the general knowledge one must have access to in order to grasp the meaning of the text (see, e.g., Garrod \& Terras, 2000; Kintsch, 1988, 1998; McKoon, Greene, \& Ratcliff, 1993; McKoon \& Ratcliff, 1988). Likewise, research on reading comprehension has shown that implicit causality is one of the factors that must be controlled in anaphoric resolution tasks, which are difficult for a large number of readers with poor comprehension (see, e.g., Ehrlich, Remond, \& Tardieu, 1999; Yuill \& Oakhill, 1988). In social psychology, implicit causality has been related to aggression and altruism. Therefore, in some studies, implicit causality has been used to investigate whether attributional roles are stable in different cultures and languages, or whether they constitute a linguistic tool (Rudolph \& Försterling, 1997a). In more recent extensions, implicit causality, along with the mechanism of cognitive balance first postulated by Heider (1958), has been used as a principle that regulates explanations of interpersonal events (see Rudolph, 1997; Rudolph \& von Hecker, 2006). Therefore, the study of implicit causality is of interest to language psychologists and social psychologists to almost the same degree.

Different methods have been used to investigate implicit causality, but one of those most frequently utilized is the language production task. These tasks generally require the participant to complete an unfinished sentence with the causal connector because, by providing a predicate that makes the potential cause of the previous event clear (see De Vega, 2005, for a study on the semantic specificity of the connector because). Some studies have included an ambiguous pronoun that requires sentence completion, as in Sentence 3 below, and others have provided the complete sentence, as in Sentence 4, and then asked

E. Goikoetxea, egoiko@fice.deusto.es 
a question (e.g., Caramazza, Grober, Garvey, \& Yates, 1977; Garvey \& Caramazza, 1974; Garvey, Caramazza, $\&$ Yates, 1974-1975). The pronouns fall into the area of pronominal anaphors ${ }^{1}$ (e.g., she, he), linguistic expressions that refer to entities previously mentioned in a text, an area that has received extensive study (e.g., Carreiras \& Alonso, 1999; Garnham, 2001; Gernsbacher, 1989; in the field of reading comprehension, see Clifton \& Duffy, 2001; Graesser, Millis, \& Zwaan, 1997).

\section{Mary criticized Ann because she ...}

4. Mary criticized Ann because she behaved very badly.

In recent studies, another type of task has been tried in which the person is told to ask questions to get more information about who instigated the causal event described in a sentence (see, e.g., Pandelaere, Hoorens, \& Peeters, 2003). Language comprehension tasks have also been used, such as timed reading tasks or plausibility judgments. The findings have shown that sentences in which the second clause is congruent with the verbal bias, as in Sentence 5 below, are read or judged more rapidly than sentences in which the second clause is incongruent with the verbal bias, as in Sentence 6 (e.g., Caramazza et al., 1977; McKoon et al., 1993). The pronoun ambiguity resolution task has also been used in studies on reaction time.

5. David congratulated Sara because she did a good job.

6. David congratulated Sara because he needed to show his appreciation.

Stewart, Pickering, and Sanford (2000) have called this effect congruent causality (see also Carreiras, Garnham, \& Oakhill, 1996; Garnham \& Oakhill, 1985; Garnham, Oakhill, \& Cruttenden, 1992; Garrod, Freudenthal, \& Boyle, 1994; Garvey et al., 1974-1975; Grober, Beardsley, \& Caramazza, 1978).

Various theories compete to explain the effect of implicit causality, the main ones being the theory of focus and the theory of integration (see Rudolph \& Försterling, 1997a). The theory of focus suggests that implicit causality has an online effect, where the causal information from the verb is used immediately to interpret the referential pronoun in the second clause (e.g., McDonald \& MacWhinney, 1995; McKoon et al., 1993; Rinck \& Bower, 1995; Stewart et al., 2000). The theory of integration suggests that the effect of implicit causality does not occur until the information from the second clause has been integrated - that is, until the second clause has been read completely (e.g., Garnham, Traxler, Oakhill, \& Gernsbacher, 1996; Stewart et al., 2000). However, these theories are not sufficient, and a complete explanation of this effect requires a more extensive theory. In this sense, recent studies have made contributions to completing the theories. For example, Guerry, Gimenes, Caplan, and Rigalleau (2006) have suggested that the theory of integration should consider that the bias observed in the continuation of incongruent predicates with the because clause may not be measured by the activation but, rather, by the difficulty of the processing associated with finding the causal property consistent with the reactor to the event.

Different taxonomies have been created to classify interpersonal verbs (Au, 1986; Brown \& Fish, 1983b; Hoffman \& Tchir, 1990; Rudolph \& Försterling, 1997a). Nevertheless, the majority of researchers in the area of language and causation have agreed with the differentiation made by Brown and Fish (1983b) between action verbs (denoting voluntary and observable actions) and state verbs (describing involuntary interactions that are not observable and sometimes are mental states). This distinction is semantic, rather than syntactic or grammatical. These categories, although useful, are not correct for all cases. For this reason, Brown and Fish (1983b) proposed two schemas for each category, using the concept of semantic roles. For action verbs, they suggested the semantic roles of agent (someone or something that provokes an action, having his or her own motives) and patient (someone or something that experiences a change in state). Thus, in Sentence 7 below, Paul has the role of agent, Albert has the role of patient, and help is an example of the verbs that have been called agent-patient (AP). Regarding these verbs, research has shown that the implicit causality is directed toward the grammatical subject of the sentence (Rudolph, 1997). Rudolph and Försterling (1997a) suggested that another schema should be added to the AP, that of agent-evocator (AE). The AE schema also consists of an agent that does something (criticize, respond), but as a reaction to a behavior or state of another (e.g., someone who makes a mistake or someone who has an answer). In these sentences, the cause is mainly attributed to the object, as in Sentence 8:

\section{Paul helped Albert because he was stronger.}

8. Mary criticized Ann because she left her keys inside the house.

On the other hand, state verbs suggest the roles of stimulus (someone or something that gives rise to a certain experience or psychological state) and experiencer (someone who has an experience). Thus, the verbs are stimulus-experiencer (SE; e.g., surprise, impress) and experiencer-stimulus (ES; e.g., admire, love). With regard to these verbs, studies have shown that a greater causal bias is assigned to the stimulus. Therefore, the cause is assigned more to the subject in SE verbs and more to the object in ES verbs (Rudolph, 1997), as in Sentences 9 and 10, respectively:

9. Paul surprised Albert because he completely cleaned his room.

10. Mary admired Ann because she bought the best chocolates.

This taxonomy with four types of verbs (AP, AE, SE, and ES), called the revised action-state taxonomy (revised action-state distinction; see Rudolph \& Försterling, 1997 a), manages to explain between $50 \%$ and $90 \%$ of the variance in the attributions made in sentences that describe 
interpersonal events, according to a review of 16 studies with a total of 256 verbs in four different languages (Chinese, Dutch, English, and German). However, there is still no consensus about the classification taxonomies of the interpersonal verbs, and some proposals suggest taking into account concepts from popular theories on the mind and behavior (folk psychology), such as intentionality and observability (e.g., Malle, 2002).

The implicit causality of the interpersonal verbs is a robust effect that has been demonstrated in different age groups - in adults (Rudolph \& Försterling, 1997a) as well as in children (e.g., Au, 1986; Corrigan \& Stevenson, 1994; see Borzone \& Silva, 2007, for a study of anaphor resolution in Spanish-speaking children). Different methods have been used, ranging from more intrusive and artificial ones that force a choice to less intrusive and more natural ones involving free choice. Different variables unrelated to the verb (e.g., sentence structure: active or passive) have been manipulated, even in sentences that describe interactions between inanimate entities (e.g., Au, 1986; Corrigan, 2001; Corrigan \& Stevenson, 1994; Frazier, Clifton, \& Randall, 1983; Garnham et al., 1992; Garvey \& Caramazza, 1974; Garvey et al., 1974-1975; Grober et al., 1978; Rudolph, 1997; Rudolph \& Försterling, 1997a). One of the variables of interest that has been manipulated is gender (Lafrance, Brownell, \& Hahn, 1997; Mannetti \& De Grada, 1991). For example, Lafrance et al. found that gender significantly affects perception of causality in the personal interactions verbs describe. Specifically, when a woman feels part of a mixed couple, she is perceived as being less responsible for causing the event than is the male. However, if she is the receiver of the action of others, she is perceived as being the one who instigated the event much more than the male is. These results are attributed to the low status and lack of power of women, as compared with men.

Likewise, the implicit causality effect has been replicated in different languages (e.g., Chinese, Dutch, English, German, and Italian) and cultures (e.g., Brown \& Fish, 1983a; Kasof \& Lee, 1993). However, the only research that has compared the effect of causality across languages has shown that although the data patterns are similar, there are differences in the strengths of the verbal bias (Rudolph \& Försterling, 1997a). These results suggest the need to obtain normative data in each language, especially when the purpose, whether in research or in practice, is to control the causal bias on verbal tasks.

Given the lack of prior studies on the implicit causality of verbs in Spanish, the main purpose of this study is to offer normative data on this effect to researchers and professionals in the different areas of psychology. To this end, two experiments were carried out. In Experiment 1, the causality of 100 verbs in Spanish in children and adults was examined, using an offline paper-and-pencil sentence completion task. In Experiment 2, the causality of 60 of the 100 verbs analyzed in Experiment 1 was examined in adults, using an online self-administered reading task, in order to obtain convergent evidence that would add robustness to the data.

\section{EXPERIMENT 1}

The aim of Experiment 1 was to examine the implicit causality of 100 verbs in Spanish. In agreement with the previous literature, if implicit causality is a consistent effect, it would be expected that a greater number of sentences would be completed using the subject in the case of AP or SE verbs (i.e., NP1 biasing). Likewise, more sentences would be completed using the object in the case of $\mathrm{AE}$ or ES verbs (i.e., NP2 biasing).

This experiment also examined the effect of the participants' gender on perception of causality in the social interactions referred to by the verbs, taking into account the results from previous studies showing that gender significantly affects the perception of causality in the personal interactions described by verbs (Lafrance et al., 1997). With the purpose of exploring the effect of gender, the sentences included two possible mixed-gender combinations: male-sentence-subject/female-sentence-object and female-sentence-subject/male-sentence-object. Lafrance et al. observed that when male actors act on females, they are perceived as more causal than when female actors act on males.

Finally, in this experiment, a typical sentence completion task was used. However, as a novelty, the requirement was introduced of circling the pronoun referent after completing the sentence. This modification reduces the disadvantages of the scoring systems used in previous studies (e.g., Garvey et al., 1974-1975), since it reduces the value of the score and increases the number of valid responses.

\section{Method}

Participants. The participants were 105 adult volunteers (76 university students, age range $=19-42$ years, $21 \%$ of them male and $79 \%$ female; and 29 professional training students, age range $=$ $20-23$ years, $3 \%$ of them male and $97 \%$ female) and 163 children (93 from the third grade, age range $=8-9$ years, $62 \%$ of them male and $38 \%$ female; 70 from the sixth grade, age range $=11-13$ years, $60 \%$ of them male and $40 \%$ female). All of the participants were native Spanish speakers, and none of them had antecedents of sensorial, neurological, or psychiatric disorders.

Materials and Design. One hundred verbs were selected from the list of German verbs by U. Rudolph (personal communication, November 3, 2005). The selection criteria were, first, belonging to one of the four types of verbs from the revised action-state taxonomy (AP, AE, SE, and ES) and, second, being as high in frequency as possible according to LEXESP (Sebastián-Gallés, Martí, Cuetos, \& Carreiras, 2000), a Spanish word pool based on a count of 5 million Spanish words. As a result, the verbs included were $25 \mathrm{AP}$ verbs (mean frequency $=91.7$ per 5 million words; range $=22.5-453.9 ; S D=$ 106.6), $25 \mathrm{AE}$ verbs (mean frequency $=25.8$; range $=2.1-145.1$; $S D=31.4), 25 \mathrm{SE}$ verbs (mean frequency $=8.1 ;$ range $=0.54-70.7$; $S D=14.5$ ), and $25 \mathrm{ES}$ verbs (mean frequency $=16.2$; range $=$ $1.2-58.2 ; S D=18.6$ ). The selection based on lexical frequency gave rise to a different number, which was not balanced, of monotransitive verbs (which take a complement) and ditransitives (which take two complements) in each category of verbs. Specifically, regarding the monotransitive type, 15 were from the AP category, 19 from the AE category, 22 from the SE category, and 21 from the ES category.

For each verb, two sentences were constructed, one with a masculine subject name and a feminine object name, and the other with a feminine subject name and a masculine object name. Both had the format "NP1 V NP2 because ..." (see Table 1). The names were 
Table 1

Examples of Experimental Sentences in Experiment 1

\begin{tabular}{ll}
\hline \multicolumn{1}{c}{ Item } & \multicolumn{1}{c}{ Verb Type } \\
\hline Helena llamó a Unai porque ... (Helena called Unai because . . .) & agent-patient \\
Jordi cuidó a Esther porque . . (Jordi took care of Esther because . . .) & agent-evocator \\
Ana aburrió a Gabriel porque . . . (Ana bored Gabriel because . . .) & stimulus-experiencer \\
Gonzalo admiró a Lucía porque . . . (Gonzalo admired Lucía because . . .) & experiencer-stimulus \\
\hline
\end{tabular}

chosen from the list of the 150 most common names of children born in Spain in the year 2005 inscribed in the Civil Registry, published by the National Institute of Statistics (www.ine.es/daco/daco42/ mnp/nomnac.htm). An effort was made to make the masculine and feminine names in each sentence similar in length. From the 200 sentences, four lists of sentences were created, with 50 verbs in each list, balancing the gender of the subject and the object among the versions with the same list of verbs. The order of the sentences in each list was the same. The participants were randomly assigned to one of the four lists of sentences.

Procedure. The participants were tested during regular class periods in their respective class groups. Each participant was given a sheet with two tasks that had to be completed in writing. The instructions for the first task were the following: "Your task consists of completing sentences. Think of a good way to complete each of the following sentences. Then, write it on the line. There are no good or bad answers, but each sentence must make sense once it is completed." The instructions for the second task were the following: "Once the sentences are completed, the task consists of circling a name. Circle the name of the person to whom the phrase you constructed refers." There was an example provided for each task, using verbs not included in the study. There was no time limit. The session lasted about $25 \mathrm{~min}$

The responses were codified in two phases. In the first phase, a judge scored each of the sentences as "NP1" (circling the subject), which was assigned a score of 1; "NP2" (circling the object), which was assigned a score of 2; "invalid" (circling both names); and "incomplete" (no name circled). In the second phase, a trained judge rated the "incomplete" sentences, scoring NP1, NP2, or invalid (incoherent or incomprehensible content) according to his or her own criteria.

An alpha level of .05 was used for all statistical decisions.

\section{Results and Discussion}

The invalid responses, $2 \%$ of the total, were eliminated from the analyses. Next, the percentages of responses with an NP1 bias out of the 100 verbs were calculated, in adults and in children. A one-way $\chi^{2}$ for each verb was calculated separately, testing the null hypothesis of equal expected frequencies across the two categories of bias responses - that is, NP1 and NP2. Appendix A presents these data in the following order. The verb appears in the first column; the second column shows the percentage of NP1 responses in the sample of adults and the probability of obtaining this percentage by chance according to the $\chi^{2}$ test. The expected implicit causality appears in the third column. When the most common response (as indicated by the percentage of NP1 responses) does not match the expected verbal bias, this is indicated in the third column by, for example, NP1 $<$ NP2. The fourth and fifth columns show the same data as those in columns two and three, but for the sample of children.

Table 2 presents the means and standard deviations for NP1 and NP2 bias responses for each type of verb as a function of age and gender. These data were analyzed by a repeated measures ANOVA, for participants $\left(F_{1}\right)$ and items $\left(F_{2}\right)$. There was a 2 (verbal bias: NP1 or NP2) $\times 2$ (type of verb: action or state) $\times 2$ (age: children or adults) $\times$ 2 (gender: masculine-feminine or feminine-masculine) design. Verbal bias and type of verb were within factors, and age and gender were between factors.

The data analysis showed a strong effect of verbal bias $\left[F_{1}(1,264)=184.42, p<.001, \eta^{2}=.411 ; F_{2}(1,96)=\right.$ $\left.31.75, p<.001, \eta^{2}=.249\right]$, with the NP1 verbs producing attributions biasing toward the subject, and the NP2 verbs biasing toward the object (the mean responses were 1.49 and 1.66 for NP1 and NP2 verbs, respectively). An examination of the direction of the bias verb by verb showed that the majority (72 of the 100 verbs in adults and 66 of the 100 verbs in children) showed the expected direction. Of these, more than half ( 49 of the 72 verbs in adults and 35 of the 66 verbs in children) showed a moderate to strong bias size $(66 \%-100 \%$ in the case of NP1 and $0 \%-34 \%$ in the case of NP2). The strength of the verbal bias obtained in Spanish is comparable to the strengths of biases obtained in other languages, such as English (Brown \& Fish,

Table 2

Means and Standard Deviations for NP1 and NP2 Bias Responses by Type of Verb, Age, and Gender

\begin{tabular}{|c|c|c|c|c|c|c|c|c|c|c|c|c|c|c|}
\hline \multirow[b]{3}{*}{ Verb Type } & \multicolumn{6}{|c|}{ Adults $(n=105)$} & \multicolumn{6}{|c|}{ Children $(n=163)$} & & \\
\hline & \multicolumn{2}{|c|}{ Male-Female } & \multicolumn{2}{|c|}{ Female-Male } & \multicolumn{2}{|c|}{ Combined } & \multicolumn{2}{|c|}{ Male-Female } & \multicolumn{2}{|c|}{ Female-Male } & \multicolumn{2}{|c|}{ Combined } & \multicolumn{2}{|c|}{ All Sample } \\
\hline & $M$ & $S D$ & $M$ & $\overline{S D}$ & $M$ & $\overline{S D}$ & $M$ & $S D$ & $M$ & $S D$ & $M$ & $S D$ & $M$ & $S D$ \\
\hline \multicolumn{15}{|c|}{ Verbal Bias NP1 } \\
\hline Action & 1.53 & 0.24 & 1.49 & 0.25 & 1.51 & 0.24 & 1.57 & 0.31 & 1.61 & 0.29 & 1.59 & 0.30 & 1.55 & 0.28 \\
\hline State & 1.39 & 0.31 & 1.47 & 0.27 & 1.43 & 0.29 & 1. & 0.28 & 1.47 & 0.2 & 1.48 & 0.28 & 1.45 & 0.29 \\
\hline Combined & 1.46 & 0.20 & 1.46 & 0.21 & 1.46 & 0.20 & 1.50 & 0.20 & 1.52 & 0.22 & 1.51 & 0.21 & 1.49 & 0.21 \\
\hline \multicolumn{15}{|c|}{ Verbal Bias NP2 } \\
\hline Action & 1.66 & 0.20 & 1.6 & 0.2 & 1.6 & 0.20 & 1.69 & 0.2 & & 0.2 & 1.6 & 0.26 & 1.67 & 0.24 \\
\hline State & 1.64 & 0.20 & 1.6 & 0.2 & 1.6 & 0.2 & 1. & 0.3 & 1. & 0. & 1.64 & 0.30 & 1.65 & 0.26 \\
\hline Combined & 1.64 & 0.19 & 1.66 & 0.21 & 1.65 & 0.20 & 1.65 & 0.21 & 1.67 & 0.24 & 1.66 & 0.22 & 1.66 & 0.21 \\
\hline
\end{tabular}


1983b) and Italian (Franco \& Arcuri, 1990). These results support findings of an effect of causality in adults (Rudolph \& Försterling, 1997a), but also show it in children, which has been demonstrated in fewer studies (e.g., Au, 1986, with 5-year-old children; Corrigan \& Stevenson, 1994, with 3- and 4-year-old children). Furthermore, the broad range within which the responses fell (from 3.9\% to $100 \%$ ) shows that implicit causality has a continuous, rather than a dichotomous, nature, a conclusion that has already been highlighted in the literature (Caramazza et al., 1977; Garvey et al., 1974-1975; Rudolph \& Försterling, 1997b).

No main effect of type of verb was found $\left(F_{\mathbf{S}}<1\right)$, nor was there any reliable effect of age in the participant analysis, although there was in the item analysis $\left[F_{1}(1,264)=\right.$ $2.98, p=.085, \eta^{2}=.011 ; F_{2}(1,96)=5.19, p<.05, \eta^{2}=$ $.051]$. Finally, contrary to previous findings (Lafrance et al., 1997), no reliable effect was found for gender of the participants in the sentence $\left(F_{\mathbf{S}}<1\right)$.

However, the interpretation of these main effects must be attenuated in light of the significant interactions. An interaction was found between verbal bias and type of verb in the participant analysis $\left[F_{1}(1,264)=8.95, p<\right.$ $\left..01, \eta^{2}=.033 ; F_{2}(1,96)=1.80, p>.10, \eta^{2}=.018\right]$. This interaction reflects a greater effect of the verbal bias for the state verbs (the mean responses were 1.45 and 1.65 for NP1 and NP2 state verbs, respectively) than for the action verbs (the mean responses were 1.55 and 1.67 for NP1 and NP2 action verbs, respectively). In fact, fewer exceptions were found to the expected verbal bias in the state verbs than in the action verbs. Out of the 50 state verbs, only 12 verbs showed biases that were not expected in adults, and 8 verbs did so in children. Out of the 50 action verbs, 16 verbs showed biases contrary to what was expected in adults, as did 26 verbs in children. One possible explanation would be that the state verbs often include value and responsibility judgments (e.g., admire, trust), which have been related to a stronger causal bias (Fillmore, 1971; Grober et al., 1978). A similar effect was described by Garvey et al. (1974-1975) in the introduction to their work, but it was not examined in the results.

The other interaction was between verbal bias and age $\left[F_{1}(1,264)=14.61, p<.001, \eta^{2}=.052 ; F_{2}(1,96)=8.53\right.$, $\left.p<.01, \eta^{2}=.082\right]$. This interaction reveals that the NP1 bias is more pronounced in adults than in children (the mean responses were 1.46 and 1.51 for adults and children, respectively), whereas the NP2 bias has a similar strength in adults and in children (the mean responses were 1.65 and 1.66 for adults and children, respectively). This result can be better understood by taking into account the explanation provided by the dynamic models of pronoun interpretation (see Badecker \& Straub, 2002; Carreiras et al., 1996; Gernsbacher, 1989; Greene, McKoon, \& Ratcliff, 1992; Sanford \& Garrod, 1989). On the basis of these models, when the bias of a verb is not strong enough, as in the aforementioned case of the NP1 biasing verbs, other both superficial and semantic variables intervene in the resolution of the pronoun. One of the variables that might best explain the results is the distance between the referent and the pronoun, already mentioned in other studies (see, e.g., Garnham, 2001, for a more complete discussion; Stewart et al., 2000; Sturt, Scheepers, \& Pickering, 2002; see also González, Cervera, \& Miralles, 1997, for a study in Spanish). Thus, when a reader does not obtain enough semantic information from the verb, he or she completes the sentence by choosing the closest referent to the pronoun.

Furthermore, an interaction was observed between type of verb and age in the participant analysis $\left[F_{1}(1,264)=\right.$ $\left.15.95, p<.001, \eta^{2}=.057 ; F_{2}<1\right]$. This interaction reveals that the children gave the state verbs more NP2 bias than the adults did (the mean responses were 1.57 and 1.53 for children and adults, respectively), whereas there were no differences in the action verbs between the children and the adults (the mean responses were 1.63 and 1.61 for children and adults, respectively). In other words, the children found that the state verbs had more NP2 bias than did the adults. This result may be linked to the greater influence of the effect of distance on the state verbs when the reader is a child.

There were no other significant main, secondary, or tertiary effects.

\section{EXPERIMENT 2}

With the aim of finding convergent evidence, the present experiment examined the influence of implicit causality when an online self-administered reading task was used. In this task, the dependent variable was the reading time of sentences containing the verbs analyzed in Experiment 1.

The sentences used were either congruent or incongruent with the implicit causality of the verb. In line with previous research, the participants would be expected to require less time to read the sentence and select the name responsible for the action when the sentences were congruent than when they were incongruent.

\section{Method}

Participants. Thirty-four university psychology students participated voluntarily (age range $=19-27$ years, $90 \%$ women); all were native Spanish speakers. The percentage of women in the sample is representative of the percentage of women who study psychology at this university. None of the participants had sensorial, neurological, or psychiatric disorders. All of the participants were different from those in Experiment 1.

Materials and Design. For practical reasons, only 60 of the 100 verbs in Experiment 1 were used. Of these 60, 40 verbs were randomly selected from the verbs that showed the expected bias (10 verbs in each category: AE, AP, SE, and ES), and 20 verbs were randomly selected from the verbs that showed a bias opposite from that expected ( 5 verbs from each category: AE, AP, SE, and ES; see Appendix B for the complete list of verbs). For each verb, 2 sentences were constructed, one congruent and one incongruent. Thus, 120 sentences were created that included a main clause with two proper names, one masculine and one feminine (or vice versa), and one subordinate clause (see Table 3 for examples of the sentences used). It is important to keep in mind that the subordinate clause (in the original Spanish version) included a zero-anaphor wherein there were no syntactic clues (i.e., pronoun gender) to solve the subordinate clause reference. The items were matched in length throughout the two conditions (see Table 4). Each sentence was followed by 
Table 3

Examples of Experimental Sentences in Experiment 2

$\frac{\text { Item }}{\text { Congruent Sentences }}$ Verb Type

Helena llamó a Unai porque tenía que decirle algo. (Helena called Unai because s/he had to tell him something.)

¿Quién tenía que decirle algo? (Who had to say something?)

Helena/Unai

Jordi cuidó de Esther porque tenía gripe. (Jordi took care of Esther because s/he had the flu.)

¿Quién tenía gripe? (Who had the flu?)

Jordi/Esther

Ana aburrió a Gabriel porque hablaba lentamente. (Ana bored Gabriel because s/he talked slowly.)

¿Quién hablaba lentamente? (Who talked slowly?)

Ana/Gabriel

Gonzalo admiró a Lucía porque hizo una gran proeza. (Gonzalo admired Lucía because s/he accomplished a great feat.)

¿Quién hizo una gran proeza? (Who accomplished a great feat?)

Gonzalo/Lucía

Incongruent Sentences

Helena llamó a Unai porque pasó a su lado sin mirar. (Helena called Unai because s/he passed by without looking.)

¿Quién pasó sin mirar? (Who passed by without looking?)

Helena/Unai

Jordi cuidó de Esther porque tenía tiempo. (Jordi took care of Esther because s/he had time.)

¿Quién tenía tiempo? (Who had time?)

Jordi/Esther

Ana aburrió a Gabriel porque ya conocía la historia. (Ana bored Gabriel because s/he already knew the story.)

¿Quién conocía la historia? (Who knew the story?)

Ana/Gabriel

Gonzalo admiró a Lucía porque valoraba la grandeza. (Gonzalo admired Lucía because s/he valued greatness.)

¿Quién valoraba la grandeza? (Who valued greatness?)

Gonzalo/Lucía

a question that included the names counterbalanced between the participants.

Procedure. The participants were tested individually or in groups of up to 25 in a quiet room, where each participant used a PC-compatible microcomputer to self-pace stimuli and give their responses. The successive stimuli were presented in black letters (Times New Roman, 14-point size) in the middle of the computer screen against a white background.

The procedure used was the following. To begin the test, the student pressed the space bar key. This activated two events: the appearance of a sentence on the screen (e.g., Ana bored Gabriel because s/he talked slowly) and the beginning of a measure that we call sentence reading time. Once the sentence had been read, the student pressed the "M" key. This activated two events: The internal clock on the computer stopped measuring the sentence reading time, and a comprehension question appeared (e.g., Who talked slowly?). Once the question had been read, the student pressed the " $M$ " key. This activated two events: the appearance of two names separated on the screen, one on the left and the other on the right (e.g., Ana/Gabriel), and the beginning of a new measure that we call response time. Once the two names had been read, the student was instructed to decide as quickly as possible which of the two names answered the question better. To choose the one on the left, the student pressed a key located on the left side of the keyboard (" $Z$ "). To choose the answer on the right, the student pressed a key located on the right side of the keyboard ("M"). When the key was pressed, the clock stopped measuring the response time, and a new sentence appeared, repeating the entire procedure again. All the stimuli (i.e., the sentence, the question, and the names) remained on the screen for 3,000 $\mathrm{msec}$ or until the participants responded, whichever came first.

Each participant received oral and written instructions and 5 practice trials before the experimental trials. Each participant received a total of 120 experimental trials: 60 congruent and 60 incongruent. The presentation of the sentences was randomized for each participant. The complete session lasted approximately $30 \mathrm{~min}$.

The presentation of the stimuli and the collection of the reaction times were controlled using DMDX display software (Forster \& Forster, 2003).

As in Experiment 1, an alpha level of .05 was used for all statistical decisions.

\section{Results and Discussion}

Sentence reading time. Sentence reading times that were more than 2.0 standard deviations above or below the mean were eliminated ( $3 \%$ of the total). Table 5 presents

Table 4

Means and Standard Deviations for Sentence and Question Lengths in Experiment 2

\begin{tabular}{|c|c|c|c|c|c|c|c|c|}
\hline \multirow[b]{3}{*}{ Verb Type } & \multicolumn{4}{|c|}{ Sentence Length } & \multicolumn{4}{|c|}{ Response Length } \\
\hline & \multicolumn{2}{|c|}{ Congruent } & \multicolumn{2}{|c|}{ Incongruent } & \multicolumn{2}{|c|}{ Congruent } & \multicolumn{2}{|c|}{ Incongruent } \\
\hline & $M$ & $S D$ & $M$ & $S D$ & $M$ & $S D$ & $M$ & $S D$ \\
\hline Agent-patient & 9.3 & 2.1 & 9.6 & 1.9 & 4.3 & 1.0 & 4.5 & 1.2 \\
\hline Agent-evocator & 9.3 & 1.9 & 9.1 & 1.4 & 4.6 & 1.0 & 4.3 & 1.0 \\
\hline Stimulus-experiencer & 8.9 & 1.7 & 9.2 & 1.4 & 4.2 & 1.0 & 4.6 & 0.8 \\
\hline Experiencer-stimulus & 9.1 & 1.1 & 9.0 & 1.2 & 4.9 & 0.8 & 4.6 & 1.1 \\
\hline
\end{tabular}


Table 5

\begin{tabular}{|c|c|c|c|c|c|c|c|c|}
\hline \multirow[b]{4}{*}{ Verb Type } & \multicolumn{8}{|c|}{$\begin{array}{l}\text { Means and Standard Deviations for Sentence Reading Time } \\
\text { Response Time (in Milliseconds) for All Verbs }(N=\mathbf{6 0})\end{array}$} \\
\hline & \multicolumn{4}{|c|}{ Sentence Reading Time } & \multicolumn{4}{|c|}{ Response Time } \\
\hline & \multicolumn{2}{|c|}{ Congruent } & \multicolumn{2}{|c|}{ Incongruent } & \multicolumn{2}{|c|}{ Congruent } & \multicolumn{2}{|c|}{ Incongruent } \\
\hline & $M$ & $S D$ & $M$ & $S D$ & $M$ & $S D$ & $M$ & $S D$ \\
\hline \multicolumn{9}{|c|}{ Verbal Bias NP1 } \\
\hline Action & $3,282.24$ & 426.06 & $3,307.66$ & 442.35 & 578.78 & 207.90 & 741.75 & 275.16 \\
\hline State & $3,358.19$ & 540.64 & $3,511.28$ & 531.70 & 651.69 & 274.88 & 744.37 & 239.35 \\
\hline Combined & $3,309.52$ & 408.00 & $3,407.43$ & 449.19 & 615.23 & 203.77 & 743.06 & 205.16 \\
\hline \multicolumn{9}{|c|}{ Verbal Bias NP2 } \\
\hline Action & $3,388.17$ & 524.97 & $3,248.76$ & 486.07 & 616.12 & 224.78 & 640.86 & 232.74 \\
\hline State & $3,249.74$ & 482.01 & $3,364.34$ & 475.20 & 647.12 & 243.47 & 641.34 & 268.82 \\
\hline Combined & $3,318.96$ & 441.13 & $3,329.38$ & 453.37 & 631.62 & 208.23 & 641.10 & 218.07 \\
\hline Total & $3,321.14$ & 387.26 & $3,422.37$ & 426.18 & 623.42 & 185.79 & 717.96 & 183.85 \\
\hline
\end{tabular}

the means of the sentence reading times for the different experimental conditions.

To examine the strength of the effects of congruence, verbal bias, and type of verb, as well as the interactions between these three factors, repeated measures ANOVAs were performed, for participants $\left(F_{1}\right)$ and items $\left(F_{2}\right)$, on the basis of the means of the sentence reading times to the sentences, with a 2 (congruence: congruent or incongruent) $\times 2$ (verbal bias: NP1 or NP2) $\times 2$ (type of verb: action or state) design.

The ANOVA on the sentence reading times revealed an effect of congruence only in the participant analysis $\left[F_{1}(1,31)=4.72, p<.05, \eta^{2}=.132 ; F_{2}(1,104)=1.17\right.$, $\left.p>.10, \eta^{2}=.011\right]$, with the congruent sentences being read more quickly $(M=3,321.14 \mathrm{msec})$ than the incongruent sentences $(M=3,422.37 \mathrm{msec})$. There were also main effects of verbal bias only in the participant analysis $\left[F_{1}(1,31)=4.40, p<.05, \eta^{2}=.124 ; F_{2}(1,104)<1\right]$, with the NP2 biasing sentences being read more quickly $(M=3,323.50 \mathrm{msec})$ than those with NP1 biasing ( $M=$ $3,353.10 \mathrm{msec})$. However, there was no significant effect of type of verb $(F \mathrm{~s}<1)$. As would be expected, the congruent sentences were read more quickly than the incongruent ones, and the verbs with NP2 biasing were processed more quickly than those with NP1 biasing (see Badecker \& Straub, 2002; Carreiras et al., 1996; Gernsbacher, 1989; Greene et al., 1992; Sanford \& Garrod,
1989; Stewart et al., 2000; see also Long \& De Ley, 2000 , for an explanation based on the greater predictive strength of the NP2 verbs, as compared with the NP1 words).

The two-way interaction between congruence and verbal bias showed a significant effect in the participant analysis $\left[F_{1}(1,31)=8.65, p<.01, \eta^{2}=.218 ; F_{2}(1,104)=\right.$ $\left.1.43, p>.10, \eta^{2}=.014\right]$. This interaction showed that the effect of congruence is stronger in NP1 biasing verbs (the mean response times were 3,309.52 and 3,407.43 msec for congruent and incongruent sentences, respectively) than in NP2 biasing verbs (the mean sentence reading times were 3,318.96 and 3,329.38 msec for congruent and incongruent sentences, respectively). No other significant interactions were found.

In order to further examine the expected effect of congruence on verb bias, the sentence reading times were analyzed for the 10 verbs in each category that showed the predicted bias in Experiment 1 (see Table 6). This ANOVA again showed, as was expected, a main effect of congruence in the participant analysis $\left[F_{1}(1,31)=20.31, p<\right.$ $\left..001, \eta^{2}=.396 ; F_{2}(1,64)=1.33, p>.10, \eta^{2}=.020\right]$, with the congruent sentences being read more quickly $(M=3,390.76 \mathrm{msec})$ than the incongruent sentences $(M=3,612.62 \mathrm{msec})$. There was also an effect of verbal bias in the participant and, marginally, the item analyses $\left[F_{1}(1,31)=14.62, p<.01, \eta^{2}=.321 ; F_{2}(1,64)=3.38\right.$, $\left.p=.07, \eta^{2}=.050\right]$. The sentences with NP2 bias were

Table 6

Means and Standard Deviations for Sentence Reading Time and Response Time (in Milliseconds) for Verbs $(N=40)$ With Predicted Biases

\begin{tabular}{|c|c|c|c|c|c|c|c|c|}
\hline \multirow[b]{3}{*}{ Verb Type } & \multicolumn{4}{|c|}{ Sentence Reading Time } & \multicolumn{4}{|c|}{ Response Time } \\
\hline & \multicolumn{2}{|c|}{ Congruent } & \multicolumn{2}{|c|}{ Incongruent } & \multicolumn{2}{|c|}{ Congruent } & \multicolumn{2}{|c|}{ Incongruent } \\
\hline & $M$ & $S D$ & $M$ & $S D$ & $M$ & $S D$ & $M$ & $S D$ \\
\hline \multicolumn{9}{|c|}{ Verbal Bias NP1 } \\
\hline Action & $3,457.47$ & 513.88 & $3,615.47$ & 588.91 & 578.78 & 207.90 & 741.75 & 275.16 \\
\hline State & $3,342.69$ & 546.46 & $3,674.83$ & 725.44 & 651.69 & 274.88 & 744.37 & 239.35 \\
\hline Combined & $3,400.08$ & 462.20 & $3,645.15$ & 591.15 & 615.23 & 203.77 & 743.06 & 205.16 \\
\hline \multicolumn{9}{|c|}{ Verbal Bias NP2 } \\
\hline Action & $3,342.80$ & 517.55 & $3,203.30$ & 474.31 & 616.12 & 224.78 & 640.86 & 232.74 \\
\hline State & $3,351.14$ & 570.68 & $3,485.35$ & 544.88 & 647.12 & 243.47 & 641.34 & 268.82 \\
\hline Combined & $3,346.97$ & 466.52 & $3,363.95$ & 488.72 & 631.62 & 208.23 & 641.10 & 218.07 \\
\hline Total & $3,390.76$ & 460.86 & $3,612.62$ & 581.20 & 623.42 & 185.79 & 717.96 & 183.85 \\
\hline
\end{tabular}


read faster $(M=3,370.69 \mathrm{msec})$ than those with NP1 bias $(M=3,522.61 \mathrm{msec})$, adding robustness to previous findings. As in previous analyses, no reliable effect was found of verb type $\left[F_{1}<1 ; F_{2}(1,64)=1.21, p>\right.$ $\left..10, \eta^{2}=.019\right]$. The interaction between congruence and verbal bias did show, however, a reliable effect only in the participant analysis $\left[F_{1}(1,31)=8.21, p<.01, \eta^{2}=\right.$ $\left..209 ; F_{2}(1,64)=2.16, p>.10, \eta^{2}=.033\right]$. Again, congruence was more influential in the verbs with NP1 bias (the mean sentence reading times were 3,400.08 and $3,645.15 \mathrm{msec}$ for congruent and incongruent sentences, respectively) than in the verbs with NP2 bias (the mean sentence reading times were 3,346.97 and 3,363.95 msec for congruent and incongruent sentences, respectively). Since verbs with NP1 bias tend to require more processing time, the addition of an incongruent sentence would make this processing more complicated and, therefore, would require even more time. Again, the interaction between congruence and type of verb was reliable in the participant analysis $\left[F_{1}(1,31)=6.99, p<.05, \eta^{2}=.184 ; F_{2}(1,64)=\right.$ $\left.1.83, p>.10, \eta^{2}=.028\right]$, with the effect of congruence being greater in the state verbs (the mean sentence reading times were 3,364.78 and 3,580.09 msec for congruent and incongruent sentences, respectively) than in the action verbs (the mean sentence reading times were $3,416.75$ and $3,434.74 \mathrm{msec}$ for congruent and incongruent sentences, respectively). This effect provides convergent evidence for the results of Experiment 1.

Response time. RTs that were more than 2.0 standard deviations above or below the mean were eliminated ( $6 \%$ of the total). The ANOVA of the RT for responding to the questions did not show any reliable main effects or interactions (see Table 5 for the means of the RT for the responses by condition). Then the RTs were chosen for the 10 verbs in each category that showed the predicted bias in Experiment 1 (see Table 6). This ANOVA showed a significant effect of congruence only in the participant analysis $\left[F_{1}(1,33)=13.29, p<.01, \eta^{2}=.287 ; F_{2}<1\right]$, with the questions about congruent sentences being responded to more rapidly $(M=623.42 \mathrm{msec})$ than the questions about incongruent sentences $(M=717.96 \mathrm{msec})$, as would be expected. The analyses also revealed main effects of verbal bias in the participant analysis $\left[F_{1}(1,33)=\right.$ 5.99, $\left.p<.05, \eta^{2}=.154 ; F_{2}<1\right]$, with questions about sentences containing NP2 biasing verbs being responded to more rapidly $(M=636.36 \mathrm{msec})$ than those that contained NP1 biasing verbs $(M=679.15 \mathrm{msec})$. This result coincides with previous findings in this same study and with the predictive strength of the NP2 bias shown by other studies (e.g., Long \& De Ley, 2000). Finally, the interaction of congruence and verbal bias approached significance $\left[F_{1}(1,33)=4.07, p=.052, \eta^{2}=.110\right.$; $\left.F_{2}(1,64)=3.89, p=.053, \eta^{2}=.057\right]$, with the congruence in the NP1 verbs being greater (the mean response times were 615.23 and $743.06 \mathrm{msec}$ for congruent and incongruent sentences, respectively) than in the verbs with NP2 bias (the mean response times were 631.62 and $641.10 \mathrm{msec}$ for congruent and incongruent sentences, respectively). This effect is equal to the one found in the analysis of sentence reading time and can be explained in the same way. There were no other significant effects or interactions.

\section{GENERAL DISCUSSION}

This study provides normative data and online measures of implicit verbal causality in Spanish. The results replicate and extend previous findings in other languages. The results of the two experiments confirm the existence, also in Spanish, of interpersonal verbs that give rise to different inferences about whether the subject or the object is perceived as the main cause of the social interaction, a phenomenon widely demonstrated in the literature since it was first described by Garvey and Caramazza (1974). Furthermore, the data replicate and extend the revised action-state taxonomy proposed by Rudolph and Försterling (1997a), based on the taxonomy by Brown and Fish (1983b), which has guided the majority of the studies in this area and establishes four types of verbs (AP, AE, SE, and ES) based on the semantic roles.

Thus, Experiment 1, in which the causality of 100 verbs was analyzed using an offline task, showed an effect of the implicit causality in the directionality of the responses that agreed with the predicted directionality (72 out of 100 in adults, 66 out of 100 in children). Verbs judged a priori as having NP1 bias (due to their semantic content, independently of syntactic criteria) produced more causal attributions to the subject, whereas the verbs judged as having NP2 bias produced more attributions to the object. Moreover, the results from Experiment 1 support the use of the revised action-state taxonomy in Spanish. The AP and SE verbs produced attributions to the subject, and the $\mathrm{AE}$ and $\mathrm{ES}$ verbs produced attributions to the object.

We also observed other interesting aspects of verbal implicit causality. First, the semantic information contained in the verbs with NP1 biasing seems weaker; that is, it generates less consensus about the attribution of the causality than does the information contained in the verbs with NP2 biasing. This finding coincides with the results from previous studies in other languages (Fillmore, 1971; Long \& De Ley, 2000; Mannetti \& De Grada, 1991). Second, the effect of causality is clearer in the state verbs than in the action verbs, which may be explained by the greater bias shown by the verbs of judgment and responsibility (Fillmore, 1971; Grober et al., 1978). Furthermore, the causal attributions are more pronounced in the state verbs than in the action verbs when the participants are adults, instead of children. In fact, although our results coincide with others about the universality of the phenomenon of implicit verbal causality with regard to age groups (Rudolph \& Försterling, 1997a), the verbal bias is more pronounced in adults than in children. This finding can be explained by the content and structure of the interpersonal lexicon, which is less developed in children than in adults (Hoffman \& Tchir, 1990). Finally, taking into account social psychology's interest in the effect of implicit verbal causality, it is interesting to highlight that in Experiment 1, we did not manage to replicate previous results on the influence of contextual factors, such as the gender of the people interacting, on causal verbal attribu- 
tion (e.g., Lafrance et al., 1997). Men and women were equally perceived as the causes of events and instigators of emotions, which could be interpreted as the existence of an equality of status and power between the men and the women in the sample in this study. One possible explanation is that a 2-point scale of verbal bias (NP1 or NP2) was probably not sensitive enough to detect the influence of the protagonists' gender. In contrast, in the study by Lafrance et al., which focused on the issue of sex-based cognitions as moderating the direction of causal attribution, the participants were required to rate on a 9-point scale the likelihood that a given actor or recipient was associated with a given interpersonal behavior.

In Experiment 2, using an online task, the effect of congruent causality emerged strongly in the data extracted from the RTS, both for reading and for response, as others have also observed (e.g., Garnham et al., 1992; Stewart et al., 2000). This effect shows that implicit causality is a determinant that affects the comprehension of the sentence. The participants required less time to read the sentence and select the appropriate referent when the sentences were congruent than when they were incongruent. One interesting result from the literature on implicit causality that was observed in this study is that the effect of causal congruence is especially strong in state verbs, as compared with action verbs, and in verbs with NP2 bias, in comparison with NP1 biasing verbs.

These results have important implications for diagnosis and intervention in reading comprehension. Thus, it would be useful to have tests that require pronoun resolution in congruent and incongruent sentences with implicit verbal causality, in order to examine the performance of people with different reading levels. In the same way, in comprehension training, it would be important to use activities or exercises that include verbs of different implicit causality, both in direction and in strength, and of different types (action, state), in order to make the students aware of the role of the verbs in the interpretation of the sentences.

One limitation of the present study is the number of verbs included. In this study 100 verbs were examined, a relatively large number as compared with previous studies (see Rudolph \& Försterling, 1997b), but a relatively small number as compared with the universe of interpersonal verbs, which, at least in the English language, is estimated to be close to 2,000 verbs (Hoffman \& Tchir, 1990). In future normative studies on implicit causality, it would be interesting to broaden the sample of interpersonal verbs. Another limitation may lie in the tasks employed. The sentence completion task is a difficult one for small children and one that is not always performed well, which may have an influence on the results (for a criticism of the use of this task in persons lacking syntactic knowledge, see Shum, 1993; Shum, Conde, \& Díaz, 1992). Likewise, the online task could be improved to collect data with greater ecological validity. To address this issue, efforts should be made to use sample passages or excerpts from published texts, rather than materials specifically created for experimental purposes, and to record the RT for the entire text, instead of a very specific part of it (i.e., sentence, question). Finally, the usefulness of the results and their possible generalization might be limited to the particular nature of the sample - that is, Spanish speakers from Spain. The question of whether similar results would be obtained from a sample of Spanish speakers outside of Spain requires further research.

In spite of the limitations of this study, we believe that offering data on the implicit causality of 100 interpersonal verbs in Spanish is quite useful for researchers who study language, causal learning and thought, and social behavior, as well as professionals involved in the diagnosis and treatment of language comprehension.

\section{AUTHOR NOTE}

This research was partially supported by Grant HU2006-13 from the Departamento de Educación, Universidades e Investigación del Gobierno Vasco. We thank Udo Rudolph for providing us with invaluable materials and the Colegio Santa María de Portugalete for their help in running participants. We also thank the three reviewers for the very helpful comments provided on the manuscript. Correspondence concerning this article should be addressed to E. Goikoetxea, Departamento de Psicopedagogía, Universidad de Deusto, Apartado 1, 48080 Bilbao, Spain (e-mail: egoiko@fice.deusto.es).

\section{REFERENCES}

AU, T. K. (1986). A verb is worth a thousand words: The causes and consequences of interpersonal events implicit in language. Journal of Memory \& Language, 25, 104-122.

BADEcker, W., \& Straub, K. (2002). The processing role of structural constraints on interpretation of pronouns and anaphors. Journal of Experimental Psychology: Learning, Memory, \& Cognition, 28, 748-769.

Borzone, A. M., \& Silva, M. L. (2007). La resolución de anáforas en niños: Incidencia de la causalidad implícita de los verbos [The resolution of anaphoras in children: Incidence of implicit causality of verbs]. Revista de Filosofía y Psicología, 15, 81-100.

Brown, R., \& Fish, D. (1983a). Are there universal schemas of psychological causality? Archives de Psychologie, 51, 145-153.

Brown, R., \& Fish, D. (1983b). The psychological causality implicit in language. Cognition, 14, 237-273.

Caramazza, A., Grober, E., Garvey, C., \& Yates, J. (1977). Comprehension of anaphoric pronouns. Journal of Verbal Learning \& Verbal Behavior, 16, 601-609.

Carreiras, M., \& Alonso, M. A. (1999). Comprensión de anáforas [Understanding anaphora]. In M. de Vega \& F. Cuetos (Eds.), Psicolingüística del español (pp. 205-230). Madrid: Trotta.

Carreiras, M., Garnham, A., \& OAKhill, J. (1996). Understanding anaphora: The role of superficial and conceptual information. In M. Carreiras, J. E. García-Albea, \& N. Sebastián-Gallés (Eds.), Language processing in Spanish (pp. 241-274). Mahwah, NJ: Erlbaum.

Clifton, C., JR., \& Duffy, S. A. (2001). Sentence and text comprehension: Roles of linguistic structure. Annual Review of Psychology, 52, 167-196.

Corrigan, R. (2001). Implicit causality in language: Event participants and their interactions. Journal of Language \& Social Psychology, 20, 285-320.

Corrigan, R., \& Stevenson, C. (1994). Children's causal attributions to states and events described by different classes of verbs. Cognitive Development, 9, 235-256.

De Vega, M. (2005). El procesamiento de oraciones con conectores adversativos y causales [Processing of sentences with causal or adversative connectives]. Cognitiva, 17, 85-108.

Ehrlich, M. F., Remond, M., \& TARdieu, H. (1999). Processing of anaphoric devices in young skilled and less skilled comprehenders: Differences in metacognitive monitoring. Reading \& Writing, 11, 29-63.

Fillmore, C. J. (1971). Verbs of judging: An exercise in semantic description. In C. J. Fillmore \& D. T. Langendoen (Eds.), Studies in linguistic semantics (pp. 272-296). New York: Holt, Rinehart \& Winston.

Forster, K. I., \& Forster, J. C. (2003). DMDX: A Windows display 
program with millisecond accuracy. Behavior Research Methods, Instruments, \& Computers, 35, 116-124.

FranCO, F., \& ARCURI, L. (1990). Effect of semantic valence on implicit causality of verbs. British Journal of Social Psychology, 29, 161-170.

Frazier, L., Clifton, C., \& Randall, J. (1983). Filling gaps: Decision principles and structure in sentence comprehension. Cognition, 13, 187-222.

GARnham, A. (2001). Mental models and the interpretation of anaphora. New York: Psychology Press.

GARNHAM, A., \& OAKHILL, J. (1985). On-line resolution of anaphoric pronouns: Effects of inference making and verb semantics. British Journal of Psychology, 76, 385-393.

Garnham, A., OAKhill, J., \& Cruttenden, H. (1992). The role of implicit causality and gender cue in the interpretation of pronouns. Language \& Cognitive Processes, 7, 231-255.

Garnham, A., Traxler, M., Oakhill, J., \& Gernsbacher, M. A. (1996). The locus of implicit causality effects in comprehension. Journal of Memory \& Language, 35, 517-543.

Garrod, S., Freudenthal, D., \& Boyle, E. (1994). The role of different types of anaphors in the on-line resolution of sentences in a discourse. Journal of Memory \& Language, 33, 39-68.

Garrod, S., \& Terras, M. (2000). The contribution of lexical and situational knowledge to resolving discourse roles: Bonding and resolution. Journal of Memory \& Language, 42, 526-544.

Garvey, C., \& CARAMAZZA, A. (1974). Implicit causality in verbs. Linguistic Inquiry, 5, 459-464.

Garvey, C., Caramazza, A., \& Yates, J. (1974-1975). Factors influencing assignment of pronoun antecedents. Cognition, 3, 227-243.

Gernsbacher, M. A. (1989). Mechanisms that improve referential access. Cognition, 32, 99-156.

González, J., Cervera, T., \& Miralles, J. L. (1997). El efecto de la distancia en la comprensión escrita de los demostrativos con valor anafórico [Effects of the distance on the comprehension of anaphoric demonstratives]. Psicothema, 9, 311-321.

Graesser, A. C., Millis, K. K., \& Zwaan, R. A. (1997). Discourse comprehension. Annual Review of Psychology, 48, 163-189.

Greene, S. B., McKoon, G., \& Ratcliff, R. (1992). Pronoun resolution and discourse models. Journal of Experimental Psychology: Learning, Memory, \& Cognition, 18, 266-283.

Grober, E. H., Beardsley, W., \& Caramazza, A. (1978). Parallel function strategy in pronoun assignment. Cognition, 6, 117-133.

Guerry, M., Gimenes, M., Caplan, D., \& Rigalleau, F. (2006). How long does it take to find a cause? An online investigation of implicit causality in sentence production. Quarterly Journal of Experimental Psychology, 59, 1535-1555.

HeIDER, F. (1958). The psychology of interpersonal relations. New York: Wiley.

HofFMAN, C., \& TCHIR, M. A. (1990). Interpersonal verbs and dispositional adjectives: The psychology of causality embodied in language. Journal of Personality \& Social Psychology, 58, 765-778.

KAsof, J., \& LeE, J. Y. (1993). Implicit causality as implicit salience. Journal of Personality \& Social Psychology, 65, 877-891.

KINTSCH, W. (1988). The role of knowledge in discourse comprehension: A construction-integration model. Psychological Review, 95 , 163-182.

KInTsCH, W. (1998). Comprehension: A paradigm for cognition. Cambridge: Cambridge University Press.

Lafrance, M., Brownell, H., \& Hahn, E. (1997). Interpersonal verbs, gender, and implicit causality. Social Psychology Quarterly, 60, 138-152.

LONG, D. L., \& DE LEY, L. (2000). Implicit causality and discourse focus: The interaction of text and reader characteristics in pronoun resolution. Journal of Memory \& Language, 42, 526-570.

Malle, B. F. (2002). Verbs of interpersonal causality and the folk theory of mind and behavior. In M. Shibatani (Ed.), The grammar of causation and interpersonal manipulation (pp. 57-83). Amsterdam: Benjamins
Mannetti, L., \& De Grada, E. (1991). Interpersonal verbs: Implicit causality of action verbs and contextual factors. European Journal of Social Psychology, 21, 429-443.

McDonald, J. L., \& MacWhinney, B. (1995). The time course of anaphor resolution: Effects of implicit verb causality and gender. Journal of Memory \& Language, 34, 543-566.

McKoon, G., Greene, S. B., \& Ratcliff, R. (1993). Discourse models, pronoun resolution, and the implicit causality of verbs. Journal of Experimental Psychology: Learning, Memory, \& Cognition, 19, 1040-1052.

McKoon, G., \& Ratcliff, R. (1988). Contextually relevant aspects of meaning. Journal of Experimental Psychology: Learning, Memory, \& Cognition, 14, 331-343.

Pandelaere, M., Hoorens, V., \& Peeters, G. (2003). Why ask about Peter? Do you think he caused it? How the description of causal events guides the selection of questions about them. Basic \& Applied Social Psychology, 25, 291-297.

RINCK, M., \& Bower, G. H. (1995). Anaphora resolution and the focus of attention in situation models. Journal of Memory \& Language, 34, 110-131.

RUDOLPH, U. (1997). Implicit verb causality: Verbal schemas and covariation information. Journal of Language \& Social Psychology, 16, 132-158.

RUdOLPH, U., \& Försterling, F. (1997a). The psychological causality implicit in verbs: A review. Psychological Bulletin, 121, 192-218.

RudOlPh, U., \& FörSTERLING, F. (1997b). Zur impliziten kausalität in sprache: Kriterien zur selection von stimulusmaterial in studien zur verbkausalität [The implicit causality in language: On the selection of stimulus materials in studies on verb causality]. Zeitschrift für Experimentelle Psychologie, 44, 293-304.

RUdOLPH, U., \& VON HeCKER, U. (2006). Three principles of explanation: Verb schemas, balance, and imbalance repair. Journal of Language \& Social Psychology, 25, 377-405.

SANFORD, A. J., \& GARROD, S. C. (1989). What, when, and how? Questions of immediacy in anaphoric reference resolution. Language \& Cognitive Processes, 4, 235-262.

Sebastián-Gallés, N., Martí, M. A., Cuetos, F., \& Carreiras, M. (2000). LEXESP: Léxico informatizado del español [LEXESP: A computerized database of Spanish]. Barcelona: Universitat de Barcelona.

SHuM, G. (1993). El pronombre en el lenguaje formal del niño [Pronouns in children's formal language]. Infancia \& Aprendizaje, 61, 107-121.

Shum, G., Conde, A., \& Díaz, C. (1992). Pautas de adquisición y uso del pronombre personal en lengua española. Un estudio longitudinal [Patterns in the acquisition and use of the personal pronoun in the Spanish language: A longitudinal study]. Estudios de Psicología, 48, 67-86.

Stewart, A. J., Pickering, M. J., \& Sanford, A. J. (2000). The time course of the influence of implicit causality information: Focusing versus integration accounts. Journal of Memory \& Language, 42, 423-443.

Sturt, P., Scheepers, C., \& Pickering, M. (2002). Syntactic ambiguity resolution after initial misanalysis: The role of recency. Journal of Memory \& Language, 46, 371-390.

YuILL, N., \& OAKHILL, J. (1988). Understanding of anaphoric relations in skilled and less skilled comprehenders. British Journal of Psychology, 79, 173-186.

\section{NOTE}

1. Implicit causality (or more generally, pragmatic inference) is not the only factor that influences the interpretation that the listeners and reader assign to the pronouns. There are at least two other factors: the restrictions imposed by the syntactic rules (e.g., gender and number of the pronoun) and the requirement that the pronouns refer to persons or objects that are in the focus of the reader's attention. 
APPENDIXA

Percentage of NP1 Responses for Each Verb According to the Type of Verb in Adults and in Children in Experiment 1

\begin{tabular}{|c|c|c|c|c|}
\hline \multirow[b]{2}{*}{ Verb } & \multicolumn{2}{|c|}{ Adults $(n=105)$} & \multicolumn{2}{|c|}{ Children $(n=163)$} \\
\hline & $\%$ NP1 & $\begin{array}{c}\text { Expected } \\
\text { Verbal } \\
\text { Bias }\end{array}$ & $\%$ NP1 & $\begin{array}{c}\text { Expected } \\
\text { Verbal } \\
\text { Bias }\end{array}$ \\
\hline \multicolumn{5}{|c|}{ Agent-Patient } \\
\hline Abandonar (abandon) & 48.1 & $\mathrm{NP} 1<\mathrm{NP} 2$ & 53.6 & NP1 \\
\hline Alcanzar (reach) & $66.7^{*}$ & NP1 & 50.0 & NP1 \\
\hline Contemplar (contemplate) & $25.9^{* *}$ & $\mathrm{NP} 1<\mathrm{NP} 2$ & $30.3^{*}$ & $\mathrm{NP} 1<\mathrm{NP} 2$ \\
\hline Decir (say) & $75.0^{* *}$ & NP1 & 66.7 & NP1 \\
\hline Dejar (leave) & 54.7 & NP1 & 56.3 & NP1 \\
\hline Demostrar (show) & $75.5^{* *}$ & NP1 & 57.1 & NP1 \\
\hline Descubrir (discover) & $35.8^{*}$ & $\mathrm{NP} 1<\mathrm{NP} 2$ & 51.9 & NP1 \\
\hline Elegir (choose) & $9.4^{* *}$ & $\mathrm{NP} 1<\mathrm{NP} 2$ & $6.3^{* *}$ & $\mathrm{NP} 1<\mathrm{NP} 2$ \\
\hline Encontrar (find) & $76.6^{* *}$ & NP1 & 46.7 & $\mathrm{NP} 1<\mathrm{NP} 2$ \\
\hline Escuchar (listen) & $33.3^{*}$ & $\mathrm{NP} 1<\mathrm{NP} 2$ & 38.7 & $\mathrm{NP} 1<\mathrm{NP} 2$ \\
\hline Evitar (avoid) & 59.3 & NP1 & $18.2^{* *}$ & $\mathrm{NP} 1<\mathrm{NP} 2$ \\
\hline Hablar (speak) & 62.3 & NP1 & 45.2 & $\mathrm{NP} 1<\mathrm{NP} 2$ \\
\hline Levantar (lift up) & $15.1^{* *}$ & $\mathrm{NP} 1<\mathrm{NP} 2$ & 44.4 & $\mathrm{NP} 1<\mathrm{NP} 2$ \\
\hline Llamar (call) & $76.5^{* *}$ & NP1 & $78.6^{* *}$ & NP1 \\
\hline Matar (kill) & 52.0 & NP1 & 45.5 & $\mathrm{NP} 1<\mathrm{NP} 2$ \\
\hline Mirar (look) & $35.3^{*}$ & NP1 $<$ NP2 & 44.4 & $\mathrm{NP} 1<\mathrm{NP} 2$ \\
\hline Pagar (pay) & $74.0^{* *}$ & NP1 & 48.3 & $\mathrm{NP} 1<\mathrm{NP} 2$ \\
\hline Pedir (ask for) & $66.7^{*}$ & NP1 & 57.1 & NP1 \\
\hline Poner (put) & $80.0^{* *}$ & NP1 & 56.7 & NP1 \\
\hline Recoger (pick up) & 37.5 & $\mathrm{NP} 1<\mathrm{NP} 2$ & $25.6^{* *}$ & $\mathrm{NP} 1<\mathrm{NP} 2$ \\
\hline Romper (break) & $84.3^{* *}$ & NP1 & 60.6 & NP1 \\
\hline Servir (serve) & 39.2 & $\mathrm{NP} 1<\mathrm{NP} 2$ & 50.0 & NP1 \\
\hline Utilizar (use) & $66.7^{*}$ & NP1 & 40.6 & $\mathrm{NP} 1<\mathrm{NP} 2$ \\
\hline $\operatorname{Ver}($ see $)$ & 46.9 & $\mathrm{NP} 1<\mathrm{NP} 2$ & 42.9 & $\mathrm{NP} 1<\mathrm{NP} 2$ \\
\hline Visitar (visit) & $25.0^{* *}$ & $\mathrm{NP} 1<\mathrm{NP} 2$ & $12.5^{* *}$ & $\mathrm{NP} 1<\mathrm{NP} 2$ \\
\hline \multicolumn{5}{|c|}{ Agent-Evocator } \\
\hline Aceptar (accept) & $66.7^{*}$ & $\mathrm{NP} 2<\mathrm{NP} 1$ & 41.4 & NP2 \\
\hline Aconsejar (advise) & 39.1 & NP2 & $30.8^{*}$ & NP2 \\
\hline Castigar (punish) & 8.7 & NP2 & $10.0^{* *}$ & NP2 \\
\hline Ceder (give in) & 60.0 & $\mathrm{NP} 2<\mathrm{NP} 1$ & 48.5 & NP2 \\
\hline Corregir (correct) & 39.2 & NP2 & 40.7 & NP2 \\
\hline Criticar (criticize) & $25.5^{* *}$ & NP2 & 36.4 & NP2 \\
\hline Cuidar (take care of) & $20.4^{* *}$ & NP2 & $19.4^{* *}$ & NP2 \\
\hline Deber (owe) & $9.3^{* *}$ & NP2 & $9.1^{* *}$ & NP2 \\
\hline Defender (defend) & $31.5^{* *}$ & NP2 & $27.3^{* *}$ & NP2 \\
\hline Detener (stop) & $21.2^{* *}$ & NP2 & $22.6^{* *}$ & NP2 \\
\hline Escapar (escape) & $32.0^{*}$ & NP2 & $26.7^{*}$ & NP2 \\
\hline Esperar (wait) & 38.3 & NP2 & 34.5 & NP2 \\
\hline Impedir (impede) & 38.0 & NP2 & 51.7 & $\mathrm{NP} 2<\mathrm{NP} 1$ \\
\hline Interrumpir (interrupt) & 53.7 & $\mathrm{NP} 2<\mathrm{NP} 1$ & 53.8 & $\mathrm{NP} 2<\mathrm{NP} 1$ \\
\hline Investigar (investigate) & 47.1 & NP2 & $36.7^{* *}$ & NP2 \\
\hline Obedecer (obey) & $25.5^{* *}$ & NP2 & $27.3^{* *}$ & NP2 \\
\hline Perseguir (chase) & 37.7 & NP2 & 40.6 & NP2 \\
\hline Proteger (protect) & $34.0^{*}$ & NP2 & $17.9^{* *}$ & NP2 \\
\hline Reaccionar (react) & 47.1 & NP2 & 44.1 & NP2 \\
\hline Rectificar (rectify) & $13.0^{* *}$ & NP2 & $17.9^{* *}$ & NP2 \\
\hline Responder (respond) & $32.0^{*}$ & NP2 & 44.8 & NP2 \\
\hline Saludar (greet) & 54.3 & $\mathrm{NP} 2<\mathrm{NP} 1$ & 62.1 & $\mathrm{NP} 2<\mathrm{NP} 1$ \\
\hline Salvar (save) & $25.9^{* *}$ & NP2 & $29.0^{*}$ & NP2 \\
\hline Seguir (follow) & 51.1 & $\mathrm{NP} 2<\mathrm{NP} 1$ & 48.4 & NP2 \\
\hline Señalar (point out) & $9.8^{* *}$ & NP2 & $25.0^{* *}$ & NP2 \\
\hline
\end{tabular}


APPENDIXA (Continued)

\begin{tabular}{|c|c|c|c|c|}
\hline \multirow[b]{2}{*}{ Verb } & \multicolumn{2}{|c|}{ Adults $(n=105)$} & \multicolumn{2}{|c|}{ Children $(n=163)$} \\
\hline & $\%$ NP1 & $\begin{array}{c}\text { Expected } \\
\text { Verbal } \\
\text { Bias }\end{array}$ & $\%$ NP1 & $\begin{array}{c}\text { Expected } \\
\text { Verbal } \\
\text { Bias }\end{array}$ \\
\hline \multicolumn{5}{|c|}{ Stimulus-Experiencer } \\
\hline Aburrir (bore) & $91.3^{* *}$ & NP1 & 64.1 & NP1 \\
\hline Afectar (affect) & $66.7^{*}$ & NP1 & 52.0 & NP1 \\
\hline Alegrar (cheer up) & 52.5 & NP1 & 61.5 & NP1 \\
\hline Alterar (alter) & $82.7^{* *}$ & NP1 & $70.0^{*}$ & NP1 \\
\hline Amenazar (threaten) & $29.4^{* *}$ & $\mathrm{NP} 1<\mathrm{NP} 2$ & 35.7 & $\mathrm{NP} 1<\mathrm{NP} 2$ \\
\hline Animar (animate) & $18.5^{* *}$ & $\mathrm{NP} 1<\mathrm{NP} 2$ & $23.3^{* *}$ & $\mathrm{NP} 1<\mathrm{NP} 2$ \\
\hline Asombrar (amaze) & $73.9^{*}$ & NP1 & $67.5^{*}$ & NP1 \\
\hline Asustar (scare) & 54.7 & NP1 & 65.5 & NP1 \\
\hline Calmar (calm down) & $4.0^{* *}$ & $\mathrm{NP} 1<\mathrm{NP} 2$ & $10.0^{* *}$ & $\mathrm{NP} 1<\mathrm{NP} 2$ \\
\hline Conmover (move) & $82.4^{* *}$ & NP1 & 65.4 & NP1 \\
\hline Desesperar (frustrate) & 65.2 & NP1 & 60.5 & NP1 \\
\hline Desmentir (deny) & 58.3 & NP1 & 59.3 & NP1 \\
\hline Distraer (distract) & $69.2^{* *}$ & NP1 & $76.0^{* *}$ & NP1 \\
\hline Disuadir (dissuade) & 43.5 & $\mathrm{NP} 1<\mathrm{NP} 2$ & 38.5 & $\mathrm{NP} 1<\mathrm{NP} 2$ \\
\hline Enseñar (teach) & 56.4 & NP1 & $12.9^{* *}$ & $\mathrm{NP} 1<\mathrm{NP} 2$ \\
\hline Entretener (entertain) & 62.0 & NP1 & 41.4 & $\mathrm{NP} 1<\mathrm{NP} 2$ \\
\hline Estimular (stimulate) & 48.1 & $\mathrm{NP} 1<\mathrm{NP} 2$ & 40.9 & $\mathrm{NP} 1<\mathrm{NP} 2$ \\
\hline Fascinar (fascinate) & $100.0^{* *}$ & NP1 & $71.1^{* *}$ & NP1 \\
\hline Formar (prepare) & 56.9 & NP1 & $20.0^{* *}$ & $\mathrm{NP} 1<\mathrm{NP} 2$ \\
\hline Impresionar (impress) & $88.0^{* *}$ & NP1 & $75.9^{* *}$ & NP1 \\
\hline Inspirar (inspire) & 62.5 & NP1 & 47.6 & $\mathrm{NP} 1<\mathrm{NP} 2$ \\
\hline Invitar (invite) & $72.3^{* *}$ & NP1 & 38.5 & $\mathrm{NP} 1<\mathrm{NP} 2$ \\
\hline Recordar (remember) & $22.0^{* *}$ & $\mathrm{NP} 1<\mathrm{NP} 2$ & 48.4 & $\mathrm{NP} 1<\mathrm{NP} 2$ \\
\hline Satisfacer (satisfy) & $66.7^{*}$ & NP1 & 47.8 & $\mathrm{NP} 1<\mathrm{NP} 2$ \\
\hline Sorprender (surprise) & 52.5 & NP1 & $70.0^{*}$ & NP1 \\
\hline \multicolumn{5}{|c|}{ Experiencer-Stimulus } \\
\hline Admirar (admire) & $5.7^{* *}$ & NP2 & $18.8^{* *}$ & NP2 \\
\hline Agradecer (thank) & 37.7 & NP2 & $26.9^{*}$ & NP2 \\
\hline Aguantar (withstand) & 52.0 & $\mathrm{NP} 2<\mathrm{NP} 1$ & 50.0 & NP2 \\
\hline Comprender (understand) & 63.3 & $\mathrm{NP} 2<\mathrm{NP} 1$ & 53.8 & $\mathrm{NP} 2<\mathrm{NP} 1$ \\
\hline Confiar (trust) & $5.0^{* *}$ & NP2 & 44.7 & NP2 \\
\hline Consentir (allow) & 43.1 & NP2 & 55.6 & $\mathrm{NP} 2<\mathrm{NP} 1$ \\
\hline Considerar (consider) & $11.5^{* *}$ & NP2 & $30.0^{*}$ & NP2 \\
\hline Despreciar (scorn) & $24.1^{* *}$ & NP2 & $15.6^{* *}$ & NP2 \\
\hline Enamorar (fall in love) & $5.7^{* *}$ & NP2 & $16.7^{* *}$ & NP2 \\
\hline Enjuiciar (judge) & $32.1^{* *}$ & NP2 & $23.8^{*}$ & NP2 \\
\hline Envidiar (envy) & $13.7^{* *}$ & NP2 & $26.7^{*}$ & NP2 \\
\hline Estimar (admire) & $27.5^{* *}$ & NP2 & 52.4 & $\mathrm{NP} 2<\mathrm{NP} 1$ \\
\hline Imaginar (imagine) & $65.4^{*}$ & $\mathrm{NP} 2<\mathrm{NP} 1$ & 36.7 & NP2 \\
\hline Molestar (bother) & $9.8^{* *}$ & NP2 & $16.0^{* *}$ & NP2 \\
\hline Olvidar (forget) & $85.0^{* *}$ & $\mathrm{NP} 2<\mathrm{NP} 1$ & 54.3 & $\mathrm{NP} 2<\mathrm{NP} 1$ \\
\hline Perdonar (forgive) & $30.2^{* *}$ & NP2 & 35.5 & NP2 \\
\hline Preferir (prefer) & $3.9^{* *}$ & NP2 & $7.4^{* *}$ & NP2 \\
\hline Preocupar (worry) & $18.9^{* *}$ & NP2 & $11.1^{* *}$ & NP2 \\
\hline Querer (love) & $17.6^{* *}$ & NP2 & $23.3^{* *}$ & NP2 \\
\hline Reconocer (recognize) & $18.9^{* *}$ & NP2 & $27.3^{* *}$ & NP2 \\
\hline Respetar (respect) & $31.1^{* *}$ & NP2 & $33.9^{*}$ & NP2 \\
\hline Soñar (dream) & 60.0 & $\mathrm{NP} 2<\mathrm{NP} 1$ & 48.6 & NP2 \\
\hline Soportar (stand) & 52.9 & $\mathrm{NP} 2<\mathrm{NP} 1$ & 41.4 & NP2 \\
\hline Temer (fear) & $11.4^{* *}$ & NP2 & $23.2^{* *}$ & NP2 \\
\hline Valorar (value) & $7.5^{* *}$ & NP2 & $26.1^{*}$ & NP2 \\
\hline
\end{tabular}

${ }^{*} p<.05 . \quad{ }^{* *} p<.01$. 


\section{APPENDIX B}

Verbs Used in Experiment 2

\section{Agent-Patient Verbs}

Verbs with expected bias: alcanzar (reach), decir (say), demostrar (show), encontrar (find), hablar (speak), llamar (call), pagar (pay), pedir (ask for), poner (put), romper (break).

Verbs with nonexpected bias: abandonar (abandon), contemplar (contemplate), elegir (choose), escuchar (listen), visitar (visit).

\section{Agent-Evocator Verbs}

Verbs with expected bias: castigar (punish), cuidar (take care of), deber (owe), detener (stop), escapar (escape), impedir (impede), investigar (investigate), perseguir (chase), responder (respond), señalar (point out).

Verbs with nonexpected bias: aceptar (accept), ceder (give in), interrumpir (interrupt), saludar (greet), seguir (follow).

\section{Stimulus-Experiencer Verbs}

Verbs with expected bias: aburrir (bore), asustar (scare), conmover (move), enseñar (teach), entretener (entertain), fascinar (fascinate), formar (prepare), inspirar (inspire), invitar (invite), satisfacer (satisfy).

Verbs with nonexpected bias: amenazar (threaten), animar (animate), calmar (calm down), estimular (stimulate), recordar (remember).

\section{Experiencer-Stimulus Verbs}

Verbs with expected bias: admirar (admire), confiar (trust), despreciar (scorn), enamorar (fall in love), enjuiciar (judge), envidiar (envy), perdonar (forgive), preocupar (worry), reconocer (recognize), temer (fear).

Verbs with nonexpected bias: aguantar (stand), comprender (understand), imaginar (imagine), olvidar (forget), soñar (dream). 